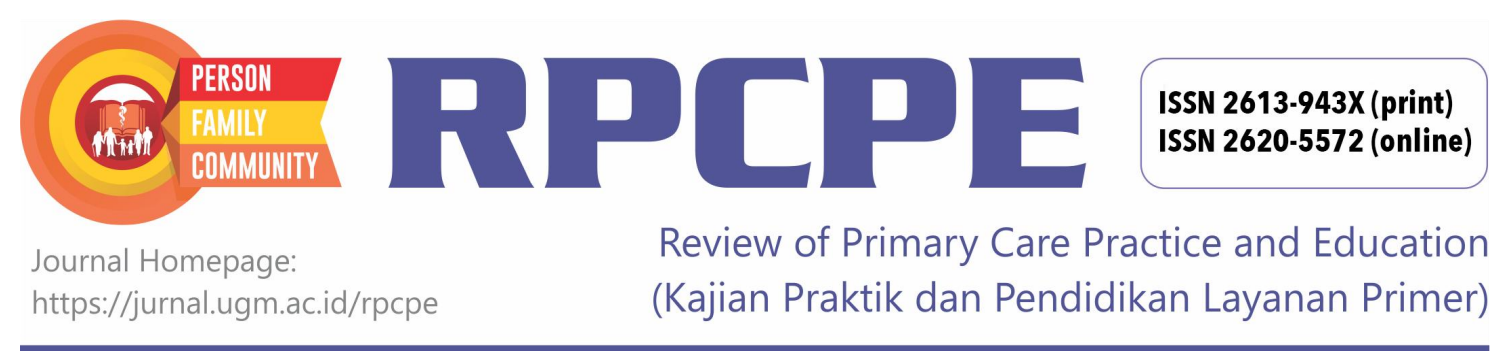

\title{
Why Does She Suffer Prolonged Status Asthmaticus?
}

\author{
Mora Claramita ${ }^{1}$, Nur Afrainin Syah $^{2}$ \begin{abstract}
Mada; Indonesia
\end{abstract} \\ ${ }^{1}$ Department of Family Medicine, Community and Bioethics; Faculty of Medicine, Public Health, and Nursing; Universitas Gadjah \\ ${ }^{2}$ Faculty of Medicine; Universitas Andalas; Indonesia
}

Corresponding Author:

Mora Claramita: Department of Medical, Health Professions Education and Bioethics; Faculty of Medicine, Public Health and Nursing; Universitas Gadjah Mada - 55281; Indonesia

Email: mora.claramita@ugm.ac.id

To cite this article:

Claramita M, Syah NA. Why does she suffer prolonged status asthmaticus?. Rev Prim Care Prac andEduc. 2019; 2(2): 83-86.

\section{CASE REPORT}

A mother (Y) aged 55 years, was hospitalized with 'Status Asthmaticus', for 4 days in a hospital, with admission through an Emergency Department Service. The case history was 'Intermittent Asthma' with corticosteroid inhaler treatment for the past three years and 'Diabetes Mellitus' (DM) Type 2, controlled by the treatment of Metformin and Acarbose. The results of the history, physical examination, and laboratory lead to the main diagnosis 'Status Asthmaticus'. Blood glucose before and when at the hospital was within normal limits (with treatment). Asthma attack was absent during the last 2 years, relapsed 2 years ago because of 'Bronchopneumonia'.

The mother (Y) lives with her husband who had been stricken with stroke and became paraplegic two years ago and was often hospitalized. The two of them were also accompanied by a nurse every day. Their first son, who had worked in Jakarta for about five years, died suddenly three months ago because of an accident. This first son left a wife and three children who live in a house near Y's house. The second son lives in a house that was rather far apart (30 minutes drive), married 2 years ago but has a problem with his mother-in-law and has no children. The mother-in-law of this second son called for 6 minutes, the day before $Y$ was admitted to the hospital. By his son, $\mathrm{Y}$ was asked what his mother-in-law said on the phone, but Y said it was fine. Every afternoon, her children, grandchildren, and two daughters-in-law always come to visit the hospital and the mother looks happy. The four siblings of Y have all married and live close to Y's house. Each of Y's siblings were able to support their economy independently.

\section{BIOLOGICAL DIAGNOSIS AND PSYCHO- SOCIAL DIAGNOSIS}

The biological diagnosis is 'Status Asthmaticus'.
Psychosocial diagnosis is a middle-aged woman who every day manages her husband who suffers from paralysis due to stroke. She is still in a phase of sadness because of the death of her first child, while her second child experiences household problems with his mother-in-law which interferes with Y's feelings, so that Y suffers addition stress from the biological problems currently experienced.

\section{FORMULATION OF THE PROBLEM}

The patient is in a phase of sadness that has lasted for approximately two years since the first nuclear family member (her husband) suffered a stroke; in this case, Y herself has been a 'caregiver' for her husband. Y's sadness coupled with the 2nd nuclear family (her first son) who died suddenly ( $\mathrm{Y}$ is still in the mourning phase), while her other son or 3rd nuclear family, had no children but had problems with his mother-in-law that resulted in household problems (she asked him to divorce). Y was also affected by her son's household conflict.

\section{DISCUSSION}

The first paragraph in the case report above is often deepened by doctors in hospitals or other doctors for further study during their medical training. On the other hand, for family doctors, the second paragraph of the case report above is the key to the patient's recovery efforts. The contents of the second paragraph presented in the case report above, is rarely a concern for basic medical education. Meanwhile from the point of view of Family Medicine, the second paragraph is essential to build a psychosocial diagnosis ${ }^{1,2,3}$.

The case illustration above continues when a 'Family Doctor' from Y, got a report from Y's son that his mother was being hospitalized. The family doctor asked about Y's problem. When being told that $\mathrm{Y}$ was hospitalized for a 'Status Asthmaticus' for already 4 days, the family doctor, in accordance with the family medicine principle and practice that he had learned, then asked some questions, both to Y's 
son, and to himself (a reflective thinking). The questioning process below is actually a clinical reasoning process which in this case involves a patient's family member, which is the main competency of a family doctor that is having good intrapersonal (self-reflection) and interpersonal (communication with others) communication skills. We can see the end result of this conversation which is very likely to be the key to healing Y:

\section{Family Doctor:}

"Mrs. $\mathrm{Y}$ is in accordance with the medical record here, and as far as I remember, her asthma rarely recurs, and has been controlled by corticosteroid inhalers for 2 years, and is currently not suffering from flu or acute respiratory infection. Is it true that the diagnosis made is only 'Status Asthmaticus'?".

"Why does she have to be hospitalized for 4 days now and possibly more, and is it not enough just to go to the emergency department and then go back home?".

"Are there any other problems, with shortness of breath? How is her heart?".

Y's Son:

"Already checked all, the results are normal".

\section{Family Doctor:}

"Why hasn't she come home, already 4 days? What is the problem?".

"It is necessary to ask the doctor who managed him, is there a problem, or can he go home soon? (To avoid the potential for nosocomial infections-doctor's reflection).

"Hmmm ... sometimes illnesses vary in severity, but I want to know what really happened to Mrs. Y?"

\section{Y's Daughter-in-Law:}

"Hmmm ... oh, the day before her asthma attack, my mother called ... - the whole story continues about the problems of her household. Until now Y's daughter-in-law cannot even do her routine work in the office because she is still bothered by her mother's attitude."

Management of Asthma Problems (Biological Problem Recognition and Management)

A woman who is hospitalized with a diagnosis of 'Status Asthmaticus' may be a common clinical problem, and such cases are commonly well learned in basic medical education and residency training. What is often discussed in such cases is of course about asthma and its complications that are relevant to the disease, maybe its differential diagnosis or how to distinguish asthma from shortness of breath because of other conditions, such as heart disease, or about managing asthma. From the perspective of the doctor in the hospital, the Y problem is 'Status Asthmaticus'. Likewise, there are the viewpoints of the Y family, and possibly $\mathrm{Y}$ herself, towards her problem. 'Status Asthmaticus' for whatever reason deserves to be considered a frightening health problem and must be immediately and properly managed because it can be life-threatening.

The following are some reviews of the diagnosis of asthma and their management in primary services:

- The Ministry of Health Republic of Indonesia, Basic Health Research 2018 shows the prevalence of asthma in Indonesia at $2.4 \%$. This figure has decreased significantly from the 2013 figure which was $4.5 \%$. The highest prevalence in 2018 is in the Special Region of Yogyakarta $(4.5 \%)$ and the lowest is in North Sumatra (1\%). The highest prevalence of asthma in the Basic Health Research 2013 was in Southeast Sulawesi and the lowest was in Lampung ${ }^{4}$.

- Asthma is a heterogeneous disease. Hypersensitive chronic airway inflammation is a characteristic of asthma. The diagnosis of asthma is based on two main features, namely respiratory complaints and limited expiratory air flow that varies from time to time and in intensity. Some factors that can cause this variation include exercise, exposure to substances such as allergens or irritants, weather changes, or viral infections in the respiratory tract ${ }^{5}$.

- The respiratory complaints and limitations of respiratory airflow can decrease or disappear spontaneously or with treatment, and can sometimes not appear for weeks or months. However, patients can experience lifethreatening exacerbations and pose a significant burden on them, their family and society ${ }^{5}$.

- Diagnosis of asthma must be accurately established before treatment is started because a diagnosis of asthma is difficult to confirm when the patient has started treatment ${ }^{5}$. Spirometry examination is needed to assess the limitations of expiratory airflow. However, this assessment is currently not available in Indonesia's primary services. Therefore, patients suspected of having asthma need to be referred to a secondary service for diagnosis.

- Management of asthma consists of the use of medications, modification of risk factors, and nonpharmacological interventions such as physical activity, diet, and weight loss 5,6 .

Psychosocial Management of the Patient (Psychosocial Problem Recognition and Management)

In the case illustration above, in addition to matters relating to disease, Family Medicine training will also discuss psychosocial disorders as a trigger of health problems experienced. This discussion is very typical for Family Medicine specialty and receives a very large portion of its residency education ${ }^{3,7,8}$. This person-based management is called a patient-centered-care management. This patientcentered care principle has been applied in the global strategy of prevention and management of asthma issued by the Global Initiative for Asthma (GINA) $)^{5,6}$. The illustration of the case above shows that even though with proper management of biological problems, 'Status Asthmaticus' can persist for several days. When psychosocial problems of patients are not well recognized, as a result healing 'Status Asthmaticus becomes less optimal.

After the Y family asked the doctor at the hospital whether $\mathrm{Y}$ was allowed to go home, Y was finally discharged from the hospital and went home even though "wheezing" was clearly heard from her breathing. The hospital doctor in 
charge advised her to rest a lot at home.

From the point of view of Family Medicine, in the case above, it is identified that $\mathrm{Y}$ is the most vulnerable family member to have health problems, because besides being a sufferer of chronic diseases (DM Type 2 and asthma), $\mathrm{Y}$ is also: (1) responsible for caregiving 'her husband; (2) within a sad period of losing her first son who has a family. The sadness cannot be shared with her husband and can only be felt by her; (3) while the second child also has a household problem, so because of the problem it adds to Y's sadness. In this case, Y can be said to almost be losing her 'whole' core family member. For a human being, Y's experience is very sad and stressful because her life partner is in pain and paralysis, the death of her first son, severe household problems of her second son, all occurred within the same year ${ }^{3}$.

The portion of biological and psychosocial health problems in a person can occur in a continuum with varying loads. Family Doctor should be able to recognize both of these problems (both small and large) carefully and strive to empower patients (and their families, if possible).

Management of psychosocial problems can be conducted with various counselling methods ${ }^{9}$. Counselling methods that can be applied include:

- Counselling with the CEA(Catharsis-Education-Action) method. Based on its name, the CEA method consists of three phases: catharsis, education, and action. Catharsis is an emotional release. According to psychoanalytic theory, this emotional release is related to the need to alleviate unconscious conflict. In the catharsis phase, a counsellor facilitates patients to clarify or define problems according to reality. The catharsis process raises and helps to ventilate hidden emotions so that they no longer interfere with the analytical function of the mind. To be able to facilitate the catharsis process, a counsellor needs to have active listening skills, empathy, and respect for any conditions. In the education phase, misperceptions are corrected using the latest scientific evidence or information available about the problem. The action phase is characterized by behavior changes. It is assumed that appropriate behavioral changes will be easier to do after the emotional burden has been released and new information and insights are given ${ }^{10,11,12}$.

- Counselling with the Mindfulness-based cognitive therapy (MBCT) method. MBCT is a type of psychotherapy that uses mindfulness practices to improve good mental and physical health. Mindfulness is a method for becoming more aware of self and the environment. Patients are asked to pay more attention to their thoughts, feelings, and physical sensations in a non-judgmental way ${ }^{13}$.

- In addition to the management of psychosocial problems, a family doctor needs to empower patients (patient empowerment), especially patients with chronic diseases, such as Mrs. Y with DM and asthma. Patient empowerment is a number of efforts that the family doctor does to make patients as active agents who have control over their own health and health care, rather than just as passive recipients of health care. Empowering patients is more than a strategy to make patients adhere to treatment, which is paternalistic in nature. Empowerment of patients, in contrast, involves an equal and mutual partnership between patients and their family doctors ${ }^{14}$. Patients empowerment strategies that can be conducted on Mrs. Y include:

- Ability to do 'maintenance' treatment of asthma and Type 2 DM regularly.

- Ability to recognize symptoms of recurrence or complications from both diseases so that she is able to timely seek appropriate help.

- Responding to other health screening efforts according to her age (e.g. Pap smears, mammography, and vaccinations).

- Having a healthy lifestyle (eating regularly and healthy, regular exercise).

- Ability to do daily living activity well and independently, including social interactions even though most of her time is spent for caregiving her husband.

- Family empowerment, by approaching the second son and daughter-in-law to continue to pay attention to Y's health, as well as the possibility of asking other relatives to stay in touch so that $\mathrm{Y}$ has the opportunity to devote his thoughts and feelings.

\section{REFERENCES}

1. McWhinney IR, Freeman T. Textbook of Family Medicine. Oxford University Press. 2009.

2. Rakel RE, Rakel DP. Textbook of Family Medicine. 8th ed. Philadelphia: Saunders. 2011.

3. McDaniel SH, Campbell TL, Hepworth J, Lorenz A. Family-oriented primary care. Springer Science \& Business Media. 2005 Dec 6.

4. Ministry of the Health Republic of Indonesia. Basic Health Research 2014. Jakarta: Health Research and Development Agency of the Ministry of the Health Republic of Indonesia. 2014.

5. Global Initiative for Asthma. Global Strategy for Asthma Management and Prevention. 2018. Available from: www.ginasthma.org

6. Reddel HK, Levy ML. The GINA asthma strategy report: what's new for primary care?. NPJ Primary Care Respiratory Medicine. 2015 Jul 30;25:15050.

7. Gan GL, Azwar A, Wonodirekso S. A primer on family medicine practice. Singapore: Singapore International Foundation. 2004.

8. Leopando ZE, et al. Textbook of family medicine. Principles, concepts, practice, and context. Manila: PAFP. 2014; 1.

9. Lukens EP, McFarlane WR. Psychoeducation as evidence-based practice: Considerations for practice, research, and policy. Brief Treatment and Crisis Intervention. 2004 Sep 1;4(3):205.

10. Dionisio A, Dionisio A. Active listening skills in health education: the CEA method. Counseling Skills for Caring Physicians: Individual Intervention. 2005:40-7.

11. Marcos AM. The effectiveness of the family catharsis education action (CEA) counseling on treatment adherence and clinical improvement among patients with pulmonary tuberculosis at the family medicine clinic of the Philippines General Hospital. Philippines: University of the Philippines. 2005.

12. Arisanti N. The effectiveness of face to face education using catharsis education action (CEA) method in improving the adherence of private general practitioners to the national guideline on management of tuberculosis in Bandung, Indonesia. Asia Pacific Family Medicine. 2012 Dec;11(1):2.

13. Sipe WE, Eisendrath SJ. Mindfulness-based cognitive therapy: theory and practice. The Canadian Journal of Psychiatry. 2012 Feb; 57(2):63-9.

14. McAllister M, Dunn G, Payne K, Davies L, Todd C. Patient empowerment: the need to consider it as a measurable patientreported outcome for chronic conditions. BMC Health Services Research. 2012 Dec;12(1):157. 
